IZA DP No. 5166

Left Behind: Intergenerational Transmission of Human Capital in the Midst of HIV/AIDS

Mevlude Akbulut-Yuksel

Belgi Turan

September 2010 


\title{
Left Behind: Intergenerational Transmission of Human Capital in the Midst of HIVIAIDS
}

\author{
Mevlude Akbulut-Yuksel \\ Dalhousie University, \\ HICN and IZA \\ Belgi Turan \\ University of Houston
}

\section{Discussion Paper No. 5166 \\ September 2010}

\author{
IZA \\ P.O. Box 7240 \\ 53072 Bonn \\ Germany \\ Phone: +49-228-3894-0 \\ Fax: +49-228-3894-180 \\ E-mail: iza@iza.org
}

Any opinions expressed here are those of the author(s) and not those of IZA. Research published in this series may include views on policy, but the institute itself takes no institutional policy positions.

The Institute for the Study of Labor (IZA) in Bonn is a local and virtual international research center and a place of communication between science, politics and business. IZA is an independent nonprofit organization supported by Deutsche Post Foundation. The center is associated with the University of Bonn and offers a stimulating research environment through its international network, workshops and conferences, data service, project support, research visits and doctoral program. IZA engages in (i) original and internationally competitive research in all fields of labor economics, (ii) development of policy concepts, and (iii) dissemination of research results and concepts to the interested public.

IZA Discussion Papers often represent preliminary work and are circulated to encourage discussion. Citation of such a paper should account for its provisional character. A revised version may be available directly from the author. 
IZA Discussion Paper No. 5166

September 2010

\section{ABSTRACT}

\section{Left Behind: Intergenerational Transmission of Human Capital in the Midst of HIVIAIDS}

This paper provides evidence on how adverse health conditions affect the transfer of human capital from one generation to the next. We explore the differential exposure to HIVIAIDS epidemic in sub-Saharan Africa as a substantial health shock to both household and community environment. We utilize the recent rounds of the Demographic and Health Surveys (DHS) for 11 countries in sub-Saharan Africa that provide information on mother's HIV status and enable us to link mothers and their children. The data also allow us to distinguish between two separate channels that are likely to differentially affect the intergenerational transfers: mother's HIV status and community HIV prevalence. First, we find that mothers transfer $37 \%$ of their human capital to their children in the developing economies in sub-Saharan Africa. Second, our results show that mother's HIV status has large detrimental effect on inheritability of human capital. HIV-infected mothers are $30 \%$ less likely to transfer their human capital to their children. Finally, focusing only on non-infected mothers and their children, we find that HIV prevalence in the community also significantly impairs the intergenerational human capital transfers even if mother is HIV negative. The findings of this paper is particularly distressing for these already poor, HIV-torn countries as in the future they will have even lower overall level of human capital due to the epidemic.

JEL Classification: $\quad 012,11,12$

Keywords: HIVIAIDS, intergenerational transmission, human capital investment

Corresponding author:

Mevlude Akbulut-Yuksel

Department of Economics

Dalhousie University

6214 University Avenue

Halifax, Nova Scotia B3H $3 \mathrm{~J} 5$

Canada

E-mail: mevlude@dal.ca

\footnotetext{
*We are especially grateful to Chinhui Juhn for very useful comments and discussions. We also thank Randall Akee, Abdurrahman Aydemir, Jane Fortson, Daniel Hamermesh, Melanie Khamis, Gary Solon, Mutlu Yuksel and seminar participants at University of Houston, Dalhousie University, IZA, 2008 SOLE and 2008 World Congress of the International Economic Association for their helpful comments and suggestions. Authors bare sole responsibility for any errors that may remain.
} 


\section{Introduction}

It has been over twenty-five years since the HIV/AIDS epidemic began; yet, it remains as one of the most serious infectious disease challenges public health. Even though the HIV prevalence has leveled off and the number of new infections has fallen, there are still 33.4 million people living with HIV across the globe, 2.7 million of which became newly infected, and 2 million people have died of AIDS in 2008 alone. HIV/AIDS is the single largest cause of mortality in sub-Saharan Africa. More than two thirds of all HIV-positive people reside in this region and this is where more than three quarters of all AIDS deaths occurred in 2008 (UNAIDS/WHO, 2009). Estimates suggest that females in sub-Saharan Africa are affected disproportionately from HIV epidemic. As a whole, women account for approximately $60 \%$ of estimated HIV infections in the region (UNAIDS, 2009). This substantial HIV prevalence among women raises serious concerns about next generations as they are the primary caregivers of children.

It is well established that there is a strong association between parent's human capital and that of their children in developed countries. This high correlation between parents' and children's human capital is attributed to the genetic transmission of ability (nature) (Becker and Tomes, 1986) or to parental wealth and care (nurture) (Sacerdote, 2007; Plug, 2004). However, the literature provides limited evidence on the potential underlying mechanisms driving this strong relation (Black and Devereux, 2010). Among others, even less is known about how adverse health conditions affect the transfer of human capital from one generation to the next.

In this paper, we first estimate the intergenerational transmission of human capital in the developing economies in sub-Saharan Africa. To the best of our knowledge, the present study is first to estimate the intergenerational transfer of human capital in the region, which has not been documented extensively due to data limitations. ${ }^{1}$ Estimating

\footnotetext{
${ }^{1}$ A notable exception studying part of African countries is Hertz et al. (2007). They estimate the intergenerational persistence of human capital in four countries in Africa including Egypt, South Africa (KwaZulu-Natal), Ghana and rural Ethiopia.
} 
the extent of intergenerational transfer of human capital in these developing economies is an important phenomenon since it enhances our understanding on inheritability of economic status in the region as education is the key ingredient of adult earnings and productivity (Card, 1999).

We next analyze how poor health conditions within the household and in the community affect the transfer of human capital from mothers to children by exploring the differential exposure to HIV epidemic. As pointed out in Black and Devereux (2010), the direction of current research on intergenerational mobility is to understand the underlying mechanisms driving the inheritability of economic and social status. This paper adds to this growing literature. The present study is first to analyze the differential exposure to disease as a potential underlying mechanism. We distinguish between two separate channels that are likely to differentially affect the intergenerational transfers, i.e. mother's HIV status and the community HIV prevalence. This enables us to disentangle household and community effects of the epidemic. Mothers who are HIV positive may transfer less of their human capital to their children due to physiological reasons, i.e. they may be too sick to educate their children. Moreover, increased risk of mortality induced by the epidemic may lead to behavioral changes even among non-infected mothers. For example, even though these mothers are healthy themselves, they may still underinvest in their children's human capital since in the disease environment their children are likely to have a shorter life span to utilize returns to their human capital investment. Developing economies in sub-Saharan Africa and other parts of the world still suffer from serious infectious diseases that challenge public health. Understanding the extent of detrimental effects of having a HIV-infected parent and/or being in a high HIV prevalence community on children's human capital accumulation, policymakers can devise better policies and programs to alleviate these long-term adverse effects.

We conduct our empirical analysis using newly available micro data from nationally representative Demographic Health Surveys (DHS) for Burkina Faso, Cameroon, Cote d'Ivorie, Ghana, Kenya, Malawi, Mali, Niger, Senegal, Zambia and Zimbabwe. In the 
latest rounds of DHS, HIV testing was administered in 17 African countries. We use 11 of these countries for which we also have an older survey that can be linked at the regional level. ${ }^{2}$ For recent waves of DHS, we are able to link mother's demographic data to her own HIV status as well as to her husband's and children's demographic data. We use earlier rounds to be able to control for unobserved heterogeneity at the regional level. This data have several advantages. First, essential to the purpose of this paper, we can link children to their parents, which is not possible in most of the available data for developing countries. Second, previous data on HIV rates are believed to be overestimating the prevalence since they were based on women attending prenatal clinics. However, our data are based on a more representative sample of the population and provide very detailed information on individuals' geographic location. Third, since our data provide information on HIV infection at the individual level, we can utilize this source of variation to examine the effects of HIV/AIDS epidemic at the household level and community level separately. Finally, availability of older surveys allows us to explore both cross-sectional variation and the long-term changes in intergenerational human capital transmission that is induced by HIV / AIDS.

To preview our results, we find that mothers transfer 37 percent of their human capital to their children in the developing economies in sub-Saharan Africa. This correlation declines to 20 percent when we control for household characteristics and community fixed effects. Moreover, our results show that mother's positive HIV status has large detrimental effect on her ability to transfer her human capital to her children. More specifically, children with HIV positive mothers are $10 \%$ less likely to inherit their mothers' human capital, which is approximately 30\% of the estimated intergenerational correlation for the entire population. Additionally, controlling for maternal education, we find that children with HIV infected mothers half as less likely to attend school and if they attend, they show slower progress at school. Robustness check shows that these

\footnotetext{
${ }^{2}$ Although we have a smaller data set when we restrict ourselves to 11 countries, the results change only slightly compared to the analysis using all countries that HIV data is available. Therefore, since this is a more robust identification, we stick to 11 country sample in the empirical analysis.
} 
results are not driven by unobserved heterogeneity.

Focusing on only non-infected mothers and their children, in both OLS and community fixed effect models, we find that the disease environment in the community hinders the transfer of human capital over generations and children's attachment to school even if mother is HIV negative. For example, in community fixed effect models, we find that children residing in a community with an average increase in HIV prevalence between two time periods are 3\% less likely to inherit their mothers' human capital, which is approximately $10 \%$ of the estimated intergenerational persistence coefficient. This is one third of the estimates from mother's HIV status analysis. Therefore, our findings suggest that a health shock experienced within the household (i.e., having a HIV-infected mother) is substantially more likely to decrease the transfer of human capital to the next generations compared to a community-wide health shock. Although the HIV prevalence in the community leads to behavioral changes even among non-infected mothers, the findings in this paper show that the pure physiological impact of the disease is primarily responsible for the detrimental effects of the epidemic.

The remainder of the paper is organized as follows. Section 2 reviews the related literature. Section 3 provides conceptual framework for the possible impacts of HIV epidemic on intergenerational transmission of human capital. Section 4 describes the data used in the analysis. Section 5 discusses the empirical strategy and presents the main results. Finally, section 6 concludes.

\section{Literature Review}

First, this study contributes to the literature on intergenerational mobility of human capital. Haveman and Wolfe (1994) review the literature and conclude that parental education is the most important factor in explaining children success at school. Among others, Couch and Dunn (1997) examine the intergenerational education correlation in the U.S. and Germany and find that children inherit around 40 percent of their parents' 
human capital in both countries. A set of studies also provide similar evidence from other countries in Europe, including Bauer and Riphahn (2007) for Switzerland; Van Ours and Veenman (2003) for the Netherlands; Hammarstedt and Palme (2005) and Osterberg (2000) for Sweden; Dustmann and Theodoropoulos (2010) for Britain; Yuksel (2009) and Dustmann (2008) for Germany. ${ }^{3}$

On the other hand, a set of studies seeks to explicitly estimate the causal association between parents' and child's human capital. Black, Devereux and Salvanes (2005) show weak evidence of a causal relationship between parental education and children's outcomes in Norway. Oreopoulos, Page and Stevens (2006), on the other hand, using various US Censuses suggest that an increase in the parental education due to the compulsory schooling laws reduces the probability of child's grade retention. Studies that focus on adoptees in the US provide further evidence on "nature" and "nurture" question (Plug and Vijverberg, 2003 and Sacerdote, 2002). Using Korean-American adoptees and parents' biological children, Sacardote (2002) finds that parental education increases adoptee's human capital; however, this increase is higher for parent's biological children. Plug and Vijverberg (2003) present similar evidence suggesting that genetically transmitted ability working through parents' income explains most of the intergenerational transmission of human capital.

Secondly, our study is closely related to the literature looking at the association between life expectancy and economic development. ${ }^{4}$ Other than directly looking at growth, more recent studies look at the determinants of growth, such as education, fertility, and labor force participation to examine the effect of improvements in health and life expectancy. Miguel and Kremer (2004) and Bleakley (2007) show that eradication of hookworm disease increased school attendance in Kenya and American South, respectively. Jayachandran and Lleras-Muney (2009) find similar evidence in Sri Lanka

\footnotetext{
${ }^{3}$ See Corak (2004) for the review of this literature.

${ }^{4}$ There is no consensus on the direction or even the existence of a correlation between life expectancy and economic growth. Shastry and Weil (2003), Weil (2007), Lorentzen, McMillan and Wacziarg (2008) find positive effects of life expectancy on economic growth, whereas, Acemoglu and Johnson (2007) find no effects.
} 
suggesting that improvements in life expectancy increased literacy and years of schooling.

As a shock to life expectancy, HIV/AIDS provides a valuable experiment to study the impact of mortality on growth. ${ }^{5}$ Mainly focusing on orphans, the existing literature has documented that HIV/AIDS epidemic has significant negative impacts on educational attainment. Case, Paxson and Ableidinger (2004) in sub-Saharan Africa, Case and Ardington (2006) in South Africa, Evans and Miguel (2007) in Kenya show that HIV/AIDS epidemic substantially hinders the human capital accumulation of orphaned children. On the other hand, a small number of studies show that HIV/AIDS epidemic has adverse effects beyond orphans through changing incentives for human capital investment among non-orphans too. For instance, Meltzer (1992) reviews the existing literature and presents estimates suggesting that the AIDS epidemic can have a strong negative effect on the incentive to invest on education. Using data from Demographic and Health Surveys (DHS) in sub-Saharan Africa, Fortson (2008) also shows that high local HIV / AIDS prevalence significantly impedes the human capital of non-orphan women born after 1980s.

Several prior studies have also analyzed the effects of HIV epidemic on fertility revisiting the question of quality-quantity trade-off in the presence of the epidemic. Using cohort-by-country variation in HIV infection and fertility, Young (2005) estimates a large negative effect of HIV prevalence on fertility. Kalemli-Ozcan and Turan (2010), on the other hand, find that if the sample is restricted to the period 1990-1998, where actual HIV data are available, the effect of HIV prevalence on fertility turns out to be positive for South Africa. Juhn, Kalemli-Ozcan and Turan (2008) show that the disease significantly lowers the fertility of infected women in sub-Saharan Africa, but local HIV prevalence

\footnotetext{
${ }^{5}$ Bloom and Mahal (1997) find that the AIDS epidemic had no effect on GDP growth. Bonnel (2000), on the other hand, shows a negative relationship. Corrigan, Gloom, and Mendez (2005) show calibration results that imply large negative effects of the epidemic on growth. Werker, Ahuja, and Wendell (2006) instrument HIV / AIDS prevalence by national circumcision rates and show that there is no impact of the epidemic on growth or savings. Papageorgiou and Stoytcheva (2008), on the other hand, find a negative effect on the level of income per capita.
} 
has no significant effect on non-infected women's fertility. Fortson (2009) confirms the lack of any significant effect on fertility. Therefore, given this empirical evidence, it is of interest to investigate whether exposure to HIV/AIDS epidemic changes mothers' incentives to transfer more or less of their human capital to their children.

\section{Conceptual Framework}

A body of theoretical models discusses the underlying mechanisms behind parent's decision on child's educational attainment. A strand of literature studies the effect of changes in child mortality on human capital investment. Ehrlich and Lui (1991), Meltzer (1992), Kalemli-Ozcan, Ryder and Weil (2000) and Kalemli-Ozcan (2002) show that improvements in life expectancy increase investment in human capital. As child mortality decreases, utility of having larger families decreases, parents have fewer children, and quantity-quality trade-off shifts towards fewer children with more education. Later, Soares (2005) shows that not only child mortality but also adult longevity is in the heart of human capital investment decision. Adult longevity is particularly important because gains in adult life expectancy increase the time horizon over which benefits of human capital investment can be realized. HIV/AIDS, in this manner, can decrease incentives for more years of schooling as both child and adult mortality increases due to epidemic. Given that life expectancy is $40-45$ years of age in many sub-Saharan countries due to the high HIV prevalence (UNPD, 2008), parents and children may prefer lower educational investment, and this may affect the intergenerational transfer of human capital.

Additionally, HIV prevalence might affect the inheritability of human capital through reductions in household income. In their empirical analysis of educational outcomes for five birth cohorts of American males, Cameron and Heckman (1998) show that longterm factors such as permanent parental income and possibly genetic family background are central for schooling decisions. From the sub-Saharan point of view, this implies that having a HIV-infected parent might affect both child's educational choices and the 
correlation between child's and parent's educational outcomes as permanent parental income decreases due to parental mortality and morbidity. Under such circumstances, child may need to drop out from school and start working as a child labor, which is a widespread phenomenon in the developing world. In fact, children's participation in the labor force exceeds 30 percent in many areas in Africa (ILO, 2008).

HIV / AIDS might also affect human capital investment through changes in the school and community environment. Deterioration along peers, teachers and other school inputs can reinforce the negative impacts of HIV on child's educational outcomes. Alternatively, parents might be less willing to send their children to school in high HIV prevalence communities due to the stigma and misconceptions associated with the epidemic. In fact, in our dataset $55 \%$ of the parents do not approve HIV positive teachers to continue teaching.

\section{Data}

We use nationally representative samples from Demographic and Health Surveys (DHS). ${ }^{6}$ DHS provides a wide range of information on individual and household characteristics of women, men and their children. In recent waves of DHS, respondents were asked to provide a few drops of their blood to be tested for HIV. The results from HIV-testing provide reliable information on individual HIV status for a representative sub-sample of women and men who are interviewed.

The strengths of this data are multifold. First of all, we can actually link children to their parents, which is not possible in most of the available data for developing countries. Most of the previous studies were able to study the intergenerational correlation using only synthetic cohorts. HIV-testing results, women/men and children surveys can all be linked by household and person identification numbers enabling us to have a cleaner identification. Secondly, all previously available HIV data were based on samples of

\footnotetext{
${ }^{6}$ DHS datasets are available at www.measuredhs.com, MEASURE DHS, Macro International Inc.
} 
pregnant women attending prenatal clinics. Timberg (2006), among others, argues that this method over-estimates HIV prevalence because pregnant women have higher risk of HIV infection since they are engaging in unprotected sex. Our data, however, are based on a representative sample of the population including both women and men. Response rate for HIV-testing is high, $86 \%$ in average, for our sample of countries as shown in Appendix A-1. One may argue that DHS estimates may be biased downwards due to the voluntary nature of the testing, however, in our view, these are the most reliable and representative estimates of HIV prevalence available to date. Thirdly, since we have HIV status of parents, we can utilize this information to examine the relationship between intergenerational transmission and parent's HIV status and distinguish it from the effect of community HIV prevalence. Finally, availability of older surveys allows us to explore both cross-sectional variation and the long-term changes in intergenerational human capital transmission that is induced by HIV/AIDS.

Our data consists of Burkina Faso (2003, 1992), Cameron (2004, 1991), Cote d'Ivorie (2005, 1994), Ghana (2003, 1993/1994), Kenya (2003, 1993), Mali (2006, 1995/1996), Malawi (2004, 1992), Niger (2006, 1992), Senegal (2005, 1992), Zambia (2007, 1992) and Zimbabwe $(2005 / 2006,1994)$. In the latest rounds of DHS, HIV testing was administered in 17 African countries; however we use 11 countries in our empirical analysis that have both a recent survey with HIV testing and an earlier wave from early 1990s. By using old surveys, first, we are able to document the intergenerational transmission of human capital in early 1990s when the HIV/AIDS was virtually negligible. Second, and most importantly, we could check robustness of our main results for regional unobserved heterogeneity by controlling for regional fixed effects and secular changes over time. Details about the surveys used in the study are given in Appendix Table A-1.

Data consist of mothers between ages 15-49 and children between ages 13-17. Mothers' human capital accumulation should be unaffected by the epidemic in order to capture the effect of HIV on transmission of human capital across generations. To account for this concern, since before 1980 HIV prevalence in sub-Saharan is negligible, only 
women who were born before 1980 and their children are used in the analysis. ${ }^{7}$ Furthermore, we exclude from the analysis children younger than 13 years of age who are likely to be at school continuing their education.

It is still likely that some of the children in our sample are still at school continuing their education. Thus, to quantify the educational progress of the children, we construct additional measure of education including school attendance and progress through school. Although these additional measures only allow us to capture the progress of the children, not the realized educational attainment, there is strong evidence suggesting that these progress outcomes are likely to correlate with other measures of children's success. The National Center for Education Statistics (1997) for example, estimates that approximately one quarter of young adults who had performed poor in progress through school dropped out of school later on.

We define these additional measures of educational attainment as follows: We assign a value of 1 to the variable "School Attendance" if the child has completed one or more years of schooling, zero otherwise. Similarly, we create a variable as "Progress through School", which is correct-grade-for-age, computed by dividing the years of schooling by years since age 7 .

Table 1a presents the descriptive statistics for mothers at 1990s and 2000s in columns (1) and (2). As aforementioned, HIV epidemic became prevalent in sub-Saharan Africa in late 1980s; therefore the analysis of 1990s provides insight on the demographics of the population in the region in the absence of the epidemic. Table 1a shows that mothers' years of schooling increased by over more than a year since 1990s. In columns (3) and (4), we compare HIV positive and HIV negative mothers using the recent waves of DHS with HIV-testing. Table 1a reveals that HIV positive mothers are more educated, wealthier, less likely to be married, work and reside in rural areas and have less children compared to HIV negative mothers.

Similarly, Table $1 \mathrm{~b}$ reports the descriptive statistics for children at 1990s and 2000s in

\footnotetext{
${ }^{7}$ Mothers who were born before 1980 account for $99 \%$ of all mothers in our sample.
} 
columns (1) and (2). Table $1 \mathrm{~b}$ points to a positive trend in educational attainment for children in sub-Saharan Africa as well, in which years of schooling increased by a year in the last decade. Moreover, columns (3) and (4) display children's characteristics by their mothers' HIV status. It seems that children with HIV positive mothers have higher years of schooling and school attendance and progress better in school.

\section{Empirical Framework and Results}

We conduct our empirical analysis in three parts. First, we estimate the intergenerational transmission of human capital in sub-Saharan Africa. Second, we examine the effect of mother's own HIV status on child's human capital controlling for mother's human capital and other household and regional characteristics. In the third part, focusing only on non-infected mothers and their children, we analyze the impact of community HIV prevalence on the transmission of human capital across generations.

\subsection{Intergenerational Transmission of Human Capital}

Before examining the effect of HIV/AIDS, we want to analyze the intergenerational transmission in developing economies in sub-Saharan Africa. We use the standard specification relating the human capital of child to the human capital of mother:

$$
{\text { Child } \text { Outcomes }_{i r c}=\alpha+\beta \text { Mother Outcomes }}_{i r c}+X_{i r c}^{\prime} \gamma+D_{r c}+D_{\text {rural }}+\epsilon_{i r c}
$$

where $i$ denotes the individual and $r c$ denotes the community, which is by country by region. Child Outcomesirc stands for child's human capital, while Mother Outcomesirc is the mother's human capital. $X_{i r c}^{\prime}$ is a vector of other covariates, and $\epsilon_{i r c}$ is a random

error term. We include a wide range of child and parental characteristics such as child's age, sex and number of siblings, mother's age, marital status, current working status 
and dummies for wealth quintile as controls. We also add dummies for community and rural residence denoted as $D_{r c}, D_{\text {rural }}$, respectively.

The coefficient $\beta$ in equation (1) measures the degree of persistence or immobility in the society and is the fraction of the mother's human capital that her child inherits. Estimates of $\beta$ close to unity imply high persistence and limited mobility, whereas values of $\beta$ close to zero suggest low persistence and almost complete intergenerational mobility in outcomes. Presumably, any real number could be obtained from the estimation of equation (1); a positive value indicates immobility where higher parental education is associated with higher child education, whereas a negative value of $\beta$ indicates a generational reversal where higher parental education is associated with lower child education. $\alpha$ compares children's educational attainment with that of their parents showing the progress through time.

Equation (1) should be regarded as a reduced-form equation, where $\beta$ being determined by multiple factors containing genetic and behavior attributes transmitted from mothers to children (nature and nurture). In this formulation, Mother Outcomes irc controls for all of the factors that affected mother's human capital, while $X_{i r c}$ includes everything else, such as the additional characteristics of the child and mother that did not affect mother's own human capital formation. Apparently, we do not observe all the characteristics of the mothers that might be correlated with child's human capital. However, ignoring $X_{i r c}$ variables that might be correlated with child's education may yield to upper bound estimates of the coefficient. Therefore, to address the potential omitted variables problem, we introduce more controls to equation (1) including family's background characteristics. We also incorporate rural and community dummies in our regressions to account for the differences across communities and different types of residence. All other remaining factors affecting children's human capital but not associated with maternal human capital are assumed to be captured by $\epsilon_{\text {irc }}$ (Aydemir, Chen and Corak, 2009).

In the intergenerational mobility literature, there is an ongoing debate on whether 
maternal or paternal education is more important for child's human capital formation. Child development literature suggests that mother's education has prime influence on child's educational attainment (Haveman and Wolfe, 1994). However, Behrman and Rosenzweig (2002), Gang and Zimmerman (2000) and Aydemir, Chen and Corak (2009) find that child's post-secondary education is positively related to that of both parents, but somewhat more strongly to fathers. To address these mixed findings in the literature, we investigate whether maternal or paternal education matters more in our setting. Results with paternal education are reported in Appendix Table A-2. Our analysis suggests that in sub-Saharan Africa, mother's education has more influence on child's human capital formation. This may stem from the fact that most of the mothers and children have low levels of education, and mother's human capital is more important for the basic human capital formation as also pointed in Pronzato (2009) using a twin fixed effect models. Therefore, in the remainder of our analysis, we use maternal education in estimating intergenerational transmission of human capital.

Table 2 reports the intergenerational transmission of human capital in sub-Saharan Africa. Panel A presents results from the recent DHS data collected in 2003-2007, while Panel B shows the analysis using 1991-1996 DHS data. HIV prevalence is assumed to be zero or negligible in sub-Saharan Africa in early 1990s; thus it is of interest to analyze the intergenerational persistence of human capital before and after HIV becomes prevalent in the region. The baseline specification that only controls for child's characteristics (reported in column (1) of Panel A) suggests that persistence coefficient for human capital is 0.37 in developing economies in sub-Saharan Africa in 2000s. In column (2), we control for household characteristics by including dummies for wealth quintile, mother's age, working and marital status and number of children to account for the fact that children's human capital may be sensitive to family background. Correlation coefficient, $\beta$ presented in column (2) is similar to the baseline specification suggesting that even after controlling for household characteristics we observe a lot of persistence in education across generations in the region. Just as importantly, to account for differences in 
educational attainment across communities and different types of residence, in column (3), we include community dummies and a rural dummy into our estimation. The coefficient estimate in column (3) drops by almost half to 0.20 once we control for regional characteristics and type of residence. This is, after controlling for household characteristics and regional heterogeneity, we find that children inherit $20 \%$ of their human capital from their mothers in the HIV-torn region after the epidemic.

This correlation coefficient is slightly lower than correlation coefficients in the US (0.46, Hertz, 2007). One of the possible reasons for this difference between our estimates and estimates for the US may stem from the fact that some of children in our sample may be still at school. This may lead to underestimation of the correlation. To minimize this potential problem, we exclude from our analysis children who are at primary-school age and younger. Given that educational attainment is low in sub-Saharan Africa (mean education is 3.6 years in mothers' generation and 4.4 years in children's generation in 2000s), we believe that we mostly capture children who completed or about to complete their human capital formation. Therefore, it is unlikely that this accounts for lower correlation between children and their mothers' education in sub-Saharan Africa. Second possible reason for lower correlation may be classical errors-in-variables problem in mother's and child's human capital. This is a particularly important concern in the estimation of the intergenerational transmission of earnings across generations (Solon, 1992). In this literature, it is important to have information on permanent income. Using information on only one year of annual earnings in the analysis of intergenerational transmission of economic outcomes can raise concerns if there is a transitory fluctuation in the annual earnings in this particular year. Previous studies address this problem by using instrumental variables or multi-year averages from panel data on individual annual earnings (Solon, 1992; Zimmermann, 1992). However, as discussed in Aydemir, Chen and Corak (2009) and Black and Devereux (2010), measurement error in an outcome like education is less of a concern compared to earnings since non-employment causes no difficulties and people tend to know their educational attainment. 
In Panel B, we analyze the intergenerational human capital persistence from earlier waves of DHS. Following the aforementioned specifications, in Panel B, we find that child inherit 42 percent of their mother's education in sub-Saharan Africa in 1990s before the HIV / AIDS epidemic became prevalent in the region. The intergenerational correlation is higher in 1990s compared to 2000s (the difference in persistence coefficient between two periods is statistically significant, where in 2000s children are 5 percent less likely to inherit their mother's human capital). A likely mechanism for change in the intergenerational mobility may be the increasing HIV prevalence in the region. Of course, it is not possible to provide definitive proof to this story, and undoubtedly additional mechanisms are at work too, but this seems to be a plausible and important mechanism for the negative trend in intergenerational mobility, which we will rigorously elaborate in the next section.

\subsection{Effect of Mother's HIV Status on Intergenerational Transmission of Human Capital}

Results from the previous section show that children inherit a substantial amount of their human capital from their mothers in the developing economies in sub-Saharan Africa. Given high rates of HIV prevalence among the prime-age women in the region, our primary interest in this paper is to determine whether mothers' HIV infection alters the human capital transfer across generations. In order to examine whether mother's HIV status impacts her ability to transfer her human capital, we allow persistence coefficient to differ between children with HIV positive and HIV negative mothers by interacting mother's human capital with her HIV status. More specifically, we estimate the following specification using 11 recent surveys with mother's HIV testing: 


\section{Child Outcomesirc $=\alpha+\beta$ Mother Outcomesirc $+\beta_{2}$ Mother Outcomesirc $*$ Mother's HIV Statusirc}

$+\theta$ Mother's HIV Status $_{i r c}+X_{i r c}^{\prime} \gamma+D_{r c}+D_{\text {rural }}+\epsilon_{\text {irc }}$

where Mother's HIV Status irc is a dummy variable that takes a value of 1 if mother $i$ in region $r c$ is HIV positive, and zero otherwise. In this specification, $\beta$ is the intergenerational correlation coefficient for the entire population, whereas $\beta_{2}$ measures whether transmission coefficient differs for children with HIV-infected mothers. Therefore, for children with HIV positive mothers, the degree of persistence can be measured by the sum of coefficients $\beta$ and $\beta_{2}$. We estimate Equation (2) following the specifications discussed in the previous section.

Table 3 shows the estimation results incorporating mother's HIV status. The differential exposure to HIV epidemic across mothers with different education and income levels can impact child's human capital along extensive margin (whether child attends school or not) and/or intensive margin (years of schooling child attain and her/his progress at school). To capture the impact of HIV epidemic on both dimensions of child's human capital formation, Panel A and Panel B report results from the analysis of child's years of schooling and progress at school, respectively, while Panel C presents the analysis for child's school attendance.

Panel A shows in all specifications that mother's positive HIV status impairs her ability to transfer her human capital. For example, children with HIV-infected mothers are $10 \%$ less likely to inherit their mother's human capital, which is approximately $30 \%$ of the estimated intergenerational persistence coefficient for the entire population in the first row. We find quantitatively similar results when we incorporate household characteristics into the baseline specification such as dummies for household wealth quintile, mother's current working and marital status and number of children (column 
(2)). The last column presents our preferred specification that also controls for regional heterogeneity and a type of residence. In this specification, we explore the variation in educational attainment between children with HIV positive and HIV negative mothers that have similar background characteristics and reside in the same community. Column (3) suggests that HIV-infected mothers are $4 \%$ less likely to transfer their human capital to their children relative to their HIV negative counterparts residing in the same community, which is one third of the estimates for the entire population in the community.

Additional analysis presented in Panel B examines progress through school as an alternative measure for child's human capital to account for the concern that some of children in our sample may be still at school continuing their education. Panel B shows that the results are qualitatively similar when the outcome of interest is progress through school. Similar to child's years of schooling, in Panel B, we find that children with HIVinfected mothers show slower progress at school compared to children of non-infected mothers. Since the analysis for "Progress through School" yields similar results, in the reminder of the paper, we will mainly focus on child's years of schooling as an outcome to be able to draw parallel conclusions to the previous literature on intergenerational mobility of human capital.

Panel $C$ shows the estimation results for the extensive margin of child's education (the outcome in Panel C is child's school attendance). Panel C displays that an additional year of maternal education increases the child's school attendance by $1 \%-4 \%$. However, children of HIV positive mothers are about half as likely to attend school for each additional year of maternal education. For instance, in column (3), we find that having a HIV-infected mother takes away the positive effects of maternal education on child's school attendance, where the coefficient for the interaction term in row (2) is negative and larger in magnitude than the coefficient of maternal education alone in row (1). Overall, findings in Table 3 suggest that the HIV/AIDS epidemic has large detrimental consequences beyond mothers' generation. Since slightly more educated and wealthier mothers are more likely to be HIV positive, as summarized in Table 1 and Table 4, HIV 
epidemic decreases the inequality in sub-Saharan Africa, per se. However, it is not that the disadvantageous population is doing any better, but the advantageous fraction of the population is worse off. Thus, these countries hard-hit by HIV epidemic are likely to suffer even more in the future from the lack of human capital in the next generations.

The OLS estimation above assumes that controlling for observables, the error term $\epsilon_{i r c}$ is uncorrelated with mother's HIV status. However, if HIV positive and negative mothers are systematically different in observable and unobservable ways, OLS estimations would be biased. To account for this concern we employ propensity score matching to ensure that mother's HIV status is random based on the distribution of observable covariates.

In Table 4, we investigate the determinants of mother's HIV status that will be used in the matching process. Table 4 reports the marginal probabilities and the associated standard errors from a reduced-form probit regression. This table shows that mother's education is significantly related to mother's HIV status with an inverted-U shape relationship where mothers with secondary education have the highest infection rates. Currently married mothers have lower infection rates than mothers who are never married or formerly married. Residence type has no significant effect on mother's HIV status. Additionally, mothers in the first two wealth quintile categories (i.e. poorest and poorer) are significantly less likely to be infected. 879 pairs of HIV positive and HIV negative mothers are matched based on the propensity scores within each region using one-to-one nearest neighbor matching without replacement. ${ }^{8}$ Table 5 mimics the specification in column (3) in Table 3 and reports the results using matched sample of 1629 mothers (the matched sample is 1758 in specification with no controls). The coefficients on interaction term in Table 5 are negative and slightly larger than main OLS results in Table 3. Table 5 suggests that children with HIV positive mothers are $6 \%$ less likely to

\footnotetext{
${ }^{8}$ We use the matching procedure developed and described by Leuven and Sianesi (2003). Simple t-tests on the equality of means between the HIV-positive and HIV-negative mothers show that our matched sample satisfies the balancing requirement, that is, there is no statistically significant differences between control and treatment group in terms of observable characteristics.
} 
have the same levels of education as their mothers compared to children with HIV negative mothers in the same community. In addition, in Panel B and Panel C, we also find that mother's HIV infection offsets the positive effect of maternal education on child's progress at school and child's school attendance. ${ }^{9}$

One of the potential mechanisms behind our findings may be the underinvestment on child's human capital in the region. This suggests that even though HIV positive mothers are decreasing their fertility as shown in Juhn, Kalemli-Ozcan and Turan (2008), they are not investing more on this fewer number of children, which contradicts with the quality-quantity trade-off theory. This decline in parental investment can be attributed to the pure physiological impact of the disease (which disables mothers to take proper care of their children), change in family structure and family income ( $70 \%$ of fathers in the households with HIV positive mothers are also HIV positive themselves) or behavioral response of mothers stemming from the increased lifetime uncertainty in the region after the onset of the epidemic. To disentangle the potential channels responsible for the estimated effects of mother's HIV status on intergenerational transmission of human capital, Table 6 reports the analysis that mimics the specification in column (3) in in Table 3. In addition, in Table 6, we also control for father's characteristics such as father's education, working, marital and HIV status, number of children and variables proxying for parental investment on child's human capital. As measures of parental investment, we use mother's frequency of reading newspaper and magazine to child and child's frequency of listening radio and watching television. As reported in Table 6, if both of the parents are HIV positive, mothers transfer only $5 \%$ of their human capital to their children, whereas the persistence coefficient is $13 \%$ if none of the parents is HIV positive. In addition, the significant negative effect of parents' HIV status on intergenerational

\footnotetext{
${ }^{9}$ Another concern is mortality. It may be the case that the HIV positive mothers in Table 3 are not a representative sample of all mothers who ever contracted the virus and that mothers who contracted the disease earlier had already died. Based on observable characteristics that are associated with mother's HIV status, those who are more likely to contract the disease and those who had already died from the disease are better educated. Therefore, if anything, our results present the lower bound for the potential negative effects of the epidemic on the inheritability of human capital.
} 
transmission of human capital remains even when we control for parental human capital investment measures. Overall, Table 6 provides suggestive evidence that it is not the change in family structure or deterioration in investment in child's human capital that is mainly responsible for estimated effects of mother's positive HIV. Likely mechanisms seem to be the physiological and behavioral impacts of the epidemic left standing. ${ }^{10}$

\subsection{Effect of Community HIV Prevalence on Intergenerational Trans- mission of Human Capital}

In the previous section, we present the estimation results from the mother's HIV status analysis. However, HIV epidemic may affect the human capital formation more broadly beyond the children of infected mothers. In this section, we will quantify the effects of growing up in a high disease prevalence and short life expectancy community on inheribility of human capital. To isolate the pure impact of the community prevalence on child's human capital formation, in this section, we restrict our analysis to children with non-infected mothers. ${ }^{11}$ We run the following regression exclusively on children with HIV negative mothers:

Child Outcomes $_{i r c}=\alpha+\beta$ Mother Outcomes $i r c+\beta_{2}$ Mother Outcomes $i r c *$ Community HIV $_{r c}$

$+\theta$ Community $H I V_{r c}+X_{i r c}^{\prime} \gamma+D_{c}+D_{\text {rural }}+\epsilon_{i r c}$

Community is country by region cells. Community HIV is defined as the fraction of adults 15-49 (both men and women) with positive HIV status in the community. Since

\footnotetext{
${ }^{10}$ Indeed, Juhn, Kalemli-Ozcan and Turan (2008) and Gray et al. (1998) suggest that physiological impacts of the disease are important for the estimated negative fertility effects of HIV epidemic.

${ }^{11}$ Results are similar when we include children with HIV positive mothers. But since, we find a significant effect of mother's HIV status in the previous section; in this part of the paper we prefer to restrict our analysis to children with HIV negative mothers only. Results including HIV positive mothers are available upon request.
} 
we control for country dummies in the above specification, $D_{c}$, we are identifying the community HIV effect from cross-regional variation in HIV prevalence and child's human capital within countries. Following Bertrand, Duflo and Mullainathan (2004), the standard errors are clustered by community to account for the correlations in outcomes between children residing in the same communities. Some descriptive statistics of communities are reported in Table 7. As Table 7 shows, community level HIV prevalence ranges from 0 to 21 percent with the average being 7 percent.

Conceptually, the effect of mother's HIV status and community level HIV prevalence can differ with the education level of parents. Generally, it is assumed that the return to education is higher for high ability children and for children of highly educated parents. Children of highly educated parents are more likely to choose higher education due to both the direct effect of having more educated parents and the indirect effect of having higher ability. Secondly, higher educated parents generally have higher incomes, increasing the resources available for child's educational attainment. Also, parental education may positively affect parental time allocation and the productivity of the parent in childenhancing activities. Finally, education may increase the bargaining power of mothers in the household. Educated mothers can direct expenditures towards child-friendly activities and investments. Therefore, through all these mechanisms, in an environment with high mortality risk, one can expect to children of highly educated parents to suffer more from the detrimental effects of the disease in the community, which we will examine in this section.

Table 8 presents evidence on how community HIV prevalence impacts intergenerational transmission of human capital among children of non-infected mothers. Column (1) suggests that HIV prevalence in the community has a negative impact on the intergenerational transfer of human capital even if mother is HIV negative. This is, a mother residing in a community with average HIV prevalence (which is $7 \%$ from Table 7 ) is $5 \%$ less likely to transfer her human capital to her children, which is approximately $25 \%$ of the estimated intergenerational persistence coefficient in the first row. The estimated neg- 
ative effects of community HIV prevalence double in communities that are most hard-hit by the epidemic. Children are $8 \%$ less likely to inherit their mothers' human capital if they reside in a community in the top HIV prevalence quartile. ${ }^{12}$ Table 8 further shows that the detrimental effects of community HIV prevalence are not limited to children's years of schooling but also impacts their school attendance and progress at school. For example, column (3) suggests that children residing in a community with average HIV prevalence are half as likely to attend school relative children in communities with zero HIV prevalence even after controlling for maternal education. It is likely that in high HIV prevalence communities, parents are less willing to send their children to school due to the decrease in incentives for education (behavioral response), credit constraints or deterioration in school environment. As stated in conceptual framework section, in our dataset $55 \%$ of the parents do not approve HIV positive teachers to continue teaching. Therefore, in high HIV prevalent environment, parents may provide basic skills to their children at home such as literacy and numeracy that would be sufficient in the labor market in sub-Saharan Africa.

OLS estimates summarized in Table 8 use the variation in HIV prevalence across regions within countries. However, the analysis on the determinants of mother's HIV status, reported on Table 4 suggests that better educated and wealthier women are more likely to be infected. Therefore, it is likely that communities with higher HIV prevalence have higher human capital endowments and economic activity. To account for the unobserved regional heterogeneity, we estimate community fixed effect models using earlier waves of DHS. More specifically, we examine whether there is a statistically significant relationship between community HIV prevalence and changes in transmission of human capital, and whether this result is robust to the inclusion of controls. In particular, we estimate the following baseline community and time period fixed effects equation:

\footnotetext{
${ }^{12}$ Additional analysis that allows the community HIV prevalence to be non-linear are available upon request.
} 


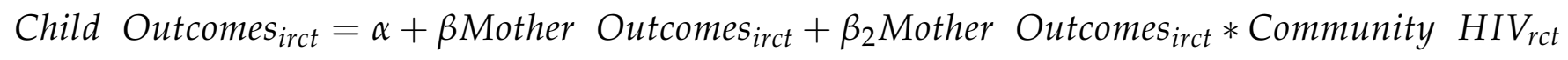

$+X_{\text {irct }}^{\prime} \gamma+D_{r c}+\zeta_{t}+D_{\text {rural }}+\epsilon_{\text {irct }}$

where $t$ refers to time period, 1991-1996 and 2003-2007. $D_{r c}$ is community fixed effects, controlling for the fact that communities may be systematically different from each other. $\zeta_{t}$ is the time-specific fixed effects, controlling for likely secular changes over time. This specification allows us to account for potential differences across communities in child's human capital formation that are not related to mothers' human capital. Therefore, controlling for other covariates, the coefficient $\beta_{2}$ measures whether persistence of human capital increased or decreased across generations in communities with higher HIV prevalence.

Table 9 presents the fixed effects analysis which controls both for regional unobserved heterogeneity and secular time trends. Like OLS results, fixed effects estimates suggest that HIV hinders the child's human capital development both along intensive and extensive margins. More specifically, children residing in a community with an average increase in HIV prevalence between two time periods (which is $7 \%$ from Table 7) are about $3 \%$ less likely to inherit their mothers' human capital, which is approximately $10 \%$ of the estimated persistence coefficient in the first row. This suggests that the coefficient on the interaction term in Table 8 declines by more than half once we account for regional unobserved heterogeneity confirming aforementioned differences across regions.

Taken together, Table 9, on the one hand, shows that community-wide health shocks may lead to behavioral responses even among non-infected mothers. This change can be attributed to the deterioration in school environment (teachers, classmates, etc.), out-ofschool environment and future socioeconomic prospects in the community. On the other 
hand, the negative effects of mother's HIV status summarized in Table 3 are substantially larger in magnitude than the community HIV prevalence reported in Table 9 suggesting that the pure physiological impact of the disease is a mediator for the detrimental effects of the epidemic.

\section{Conclusion}

The literature on education and intergenerational mobility has established that there is a strong correlation between parent's human capital and that of their children. Recently, however, the literature seeks to understand the causal mechanisms that underlie this relationship. This paper adds to this growing literature by analyzing the differential exposure to disease as a potential underlying mechanism. More specifically, using Demographic Health Surveys (DHS) for 11 countries in sub-Saharan Africa, we study the effect of HIV/AIDS on intergenerational transmission of education by distinguishing between the effect of mother's HIV status and the community prevalence rate.

First, we find that mothers transfer 37 percent of their human capital to their children in the developing economies in sub-Saharan Africa. This correlation declines to $20 \%$ when we control for household characteristics and community dummies. Second, we find that children of HIV positive mothers are 10\% less likely to inherit their mothers' human capital, which is $30 \%$ of the estimated intergenerational persistence coefficient for the entire population. Additionally, controlling for maternal education, we find that children with HIV-infected mothers are less likely to attend school and show slower progress at school. Robustness checks show that these results are not driven by unobserved heterogeneity. Finally, both OLS and community fixed effect models suggest that the disease environment in the community also hinders the transfer of human capital over generations and children's attachment to school. Since slightly better educated and wealthier mothers are more likely to be HIV-infected and communities with higher human capital endowments have higher HIV prevalence, HIV epidemic decreases the 
inequality in sub-Saharan Africa, per se. However, it is not that the disadvantageous population is doing any better, but the advantageous fraction of the population is worse off and accumulation of human capital in these countries suffers as result of HIV/AIDS.

The findings of this paper are in accord with the existing literature stating the detrimental impact of HIV/AIDS on accumulation of human capital and underlining the importance of combat against HIV/AIDS, which must be a first order policy concern as epidemic has impacts beyond the current generation. Given that almost half of the African population is children, and that the high incidence of HIV/AIDS is leading to a decrease in the middle-age population, all accounts suggest that dramatic steps are required to aggressively curb further loss of human capital accumulation and step up efforts to ensure that all African children can grow up to lead productive and healthy lives. 


\section{References}

Acemoglu, Daron and Johnson, Simon, 2007. Disease and Development: The Effect of Life Expectancy on Economic Growth. Journal of Political Economy 115(6), 925985.

Anger, Silke and Heineck, Guido, 2009. Do Smart Parents Raise Smart Children? The Intergenerational Transmission of Cognitive Abilities. SOEP, DIW Working Paper No. 156.

Aydemir, Abdurahman, Chen, Wen-Hao and Corak, Miles, 2009. Intergenerational Earnings Mobility among the Children of Canadian Immigrants. Review of Economics and Statistics 91(2), 377-397.

Bauer, Philipp and Riphahn, Regina T., 2007. Heterogeneity in the Intergenerational Transmission of Educational Attainment: Evidence from Switzerland on Natives and Second Generation Immigrants. Journal of Population Economics 20(1), 121-148.

Becker, Gary S. and Tomes, Nigel, 1986. Human Capital and the Rise and Fall of Families. Journal of Labor Economics 4(3), 1-39.

Behrman, Jere R. and Rosenzweig, Mark R., 2002. Does Increasing Women's Schooling Raise the Schooling of the Next Generation? American Economic Review 92(1), 323-334.

Bertrand, Marrianne; Duflo Ester and Mullainathan, Sendhil, 2004. How Much Should We Trust Difference-in-Difference Estimates? Quarterly Journal of Economics 119(1), 249-275.

Black, Sandra and Devereux, Paul J., 2010. Recent Developments in Intergenerational Mobility. Handbook of Labor Economics, forthcoming. 
Black, Sandra, Devereux, Paul J. and Salvanes, Kjell G., 2005. Why the Apple Doesn't Fall Far: Understanding the Intergenerational Transmission of Education. American Economic Review 95(1), 437-449.

Bleakley, Hoyt, 2007. Disease and Development: Evidence from Hookworm Eradication in the American South. Quarterly Journal of Economics 122(1), 73-117.

Bloom David and Mahal Ajay, 1997. Does the AIDS Epidemic Threaten Economic Growth? Journal of Econometrics 77(1), 105-124.

Bonnel, Renï $£_{\mathrm{i}}$, 2000. HIV/AIDS and Economic Growth: A Global Perspective. South African Journal of Economics 68(5), 360-379.

Cameron, Stephen V. and Heckman, James J., 1998. Life Cycle Schooling and Dynamic Selection Bias: Models and Evidence for Five Cohorts of American Males. Journal of Political Economy 106(2), 262-333.

Card, David, 1999. The Causal Effect of Education on Earnings. In Handbook of Labor Economics Volume 3A ed. Orley Ashenfelter and David Card, 1801-1863, Amsterdam: Elsevier.

Case, Anne and Ardington, Cally, 2006. The Impact of Parental Death on School Outcomes: Longitudinal Evidence from South Africa. Demography 43(3), 401-420.

Case, Anne, Paxson, Christina and Ableidinger, Joseph, 2004. Orphans in Africa: Parental Death, Poverty, and School Enrollment. Demography 41(3), 483-508.

Corak, Miles, 2004. Generational Income Mobility in North America and Europe. Cambridge: Cambridge University Press.

Corrigan Paul, Gloom Gerhard, Mendez Fabio, 2005. AIDS Crisis and Growth. Journal of Development Economics 77(1), 107-124. 
Couch, Kenneth A. and Dunn, Thomas A., 1997. Intergenerational Correlations in Labor Market Status. A Comparison of the United States and Germany. Journal of Human Resources 32(1), 210-232.

Dustmann, Christian, 2008. Intergenerational Mobility and Return Migration: Comparing Sons of Foreign and Native Born Fathers. Journal of Human Resources 43(2), 660-687.

Dustmann, Christian and Theodoropoulos, Nikolaos, 2010. Ethnic Minority Immigrants and their Children in Britain. Oxford Economic Papers, 62(2), 209-233.

Ehrlich, Isaac and Lui, Francis T., 1991. Intergenerational Trade, Longevity, and Economic Growth. Journal of Political Economy 99(5), 1029-1059.

Evans, David K., and Miguel, Edward, 2007. Orphans and Schooling in Africa: A Longitudinal Analysis. Demography 44(1), 35-57.

Fortson, Jane, 2008. Mortality Risk and Human Capital Investment: The Impact of HIV / AIDS in Sub-Saharan Africa. Review of Economics and Statistics, forthcoming.

Fortson, Jane, 2009. HIV / AIDS and Fertility. American Economic Journal: Applied Economics 1(3), 170-194.

Gang, Ira N. and Zimmermann, Klaus F., 2000. Is Child Like Parent? Educational Attainment and Ethnic Origin. Journal of Human Resources 35(3), 550-569.

Gray, Ronald H., Maria J. Wawer, David Serwadda, Nelson Sewankambo, Chuanjun Li, Frederick Wabwire-Mangen, Lynn Paxton, Noah Kiwanuka, Godrey Kigozi, Joseph Konde-Lule, Thomas C. Quinn, Charlotte A. Gaydos, and Denise McNairn, 1998. Population-Based Study of Fertility in Women with HIV-1 Infection in Uganda. The Lancet 351, 98-103. 
Hammarstedt, Mats and Palme, Marten, 2005. Intergenerational Mobility, Human Capital Transmission and the Earnings of Second-Generation Immigrants in Sweden. IZA Discussion Papers: No. 1943.

Haveman, Robert and Wolfe, Barbara, 1994. Succeeding Generations: On the Effects of Investments in Children. New York: Russell Sage Foundation.

Hertz, Tom, Jayasundera, Tamara, Piraino, Patrizio, Selcuk, Sibel, Smith, Nicole, and Verashchagina, Alina 2007. The Inheritance of Educational Inequality: International Comparisons and Fifty-Year Trends. The B. E. Journal of Economic Analysis \& Policy 7(2), Article 10.

Jayachandran, Seema and Lleras-Muney, Adriana, 2009. Life Expectancy and Human Capital Investments: Evidence from Maternal Mortality Declines. Quarterly Journal Economics 124(1), 349-398.

Juhn, Chinhui, Kalemli-Ozcan, Sebnem and Turan, Belgi, 2008. HIV and Fertility in Africa: First Evidence from Population Based Surveys. NBER Working Paper 14248.

International Labor Organization Child Labor, 2008.

Kalemli-Ozcan, Sebnem, Ryder, Harl and Weil, David N., 2000. Mortality Decline, Human Capital Investment and Economic Growth. Journal of Development Economics 62(1), 1-23.

Kalemli-Ozcan, Sebnem, 2002. Does Mortality Decline Promote Economic Growth? Journal of Economic Growth 7(4), 411-439.

Kalemli-Ozcan, Sebnem and Turan, Belgi, 2010. HIV and Fertility Revisited. Journal of Development Economics, forthcoming.

Leuven Edwin and Sianesi Barbara, 2003. PSMATCH2: Stata Module to Perform Full Mahalanobis and Propensity Score Matching, Common Support Graphing, and Covariate Imbalance Testing. 
Lorentzen, Peter, McMillan, John and Wacziarg, Romain, 2008. Death and Development. Journal of Economic Growth 13(1), 81-124.

Meltzer, David, 1992. Mortality Decline, the Demographic Transition and Economic Growth. PhD Dissertation, University of Chicago.

Miguel, Edward, and Kremer, Michael, 2004. Worms: Identifying Impacts on Education and Health in the Presence of Treatment Externalities. Econometrica 72(1), 159-217.

National Center for Education Statistics. 1995. Dropout Rates in the United States. NCES Research Paper, No: 97-473.

Oreopoulos, Philip; Page, Marianne and Stevens, Ann H., 2006. Does Human Capital Transfer from Parent to Child? The Intergenerational Effects of Compulsory Schooling. Journal of Labor Economics 24(4), 729-760.

Oster, Emily, 2005. Sexually Transmitted Infections, Sexual Behavior, and the HIV/AIDS Epidemic. Quarterly Journal of Economics 120(2), 467-515.

Osterberg, Torun, 2000. Economic Perspectives on Immigrants and Intergenerational Transmissions. PhD Dissertation. Economic Studies No. 102, University of Gothenburg.

Papageorgiou Chris and Stoytcheva Petia, 2008. What is the Impact of AIDS on CrossCountry Income So Far? Evidence From Newly Reported AIDS Cases. Working Paper.

Plug, Erik, 2004. Estimating the Effect of Mother's Schooling on Children's Schooling Using a Sample of Adoptees. American Economic Review 94(1), 358-68.

Plug, Erik and Vijverberg, Wim, 2003. Schooling, Family Background, and Adoption: Is It Nature or Is It Nurture. Journal of Political Economy 111(3), 611-641.

Pronzato, Chiara, 2009. An Examination of Paternal and Maternal Intergenerational Transmission of Schooling. Journal of Population Economics, forthcoming. 
Sacerdote, Bruce, 2002. The Nature and Nurture of Economic Outcomes. American Economic Review Papers and Proceedings 92(2), 344-348.

Sacerdote, Bruce, 2007. How Large are the Effects from Changes in Family Environment? A study of Korean American Adoptees. Quarterly Journal of Economics 122(1), 119-157.

Shastry, G. Kartini, and Weil, David N., 2003. How Much of the Cross-Country Variation in Income is Explained by Health? Journal of the European Economic Association 1(2-3), 387-396.

Shemyakina, Olga, 2006. The Effect of Armed Conflict on Accumulation of Schooling: Results from Tajikistan. Households in Conflict Network Working Paper 12.

Soares, Rodrigo R., 2005. Mortality Reductions, Educational Attainment, and Fertility Choice. American Economic Review 95(3), 580-601.

Solon, Gary R., 1992. Intergenerational Income Mobility in the United States. American Economic Review 82(3), 393-408.

Timberg, Craig, 2006. How AIDS in Africa Was Overstated. Washington Post.

UNAIDS/WHO AIDS Epidemic Updates, 2009.

United Nations Population Division, 2008. World Population Prospects.

Van Ours, Jan C. and Veenman, Justus, 2003. The Educational Attainment of Second Generation Immigrants in the Netherlands. Journal of Population Economics 16(4), 739-753.

Weil, David N., 2007. Accounting for the Effect of Health on Economic Growth. Quarterly Journal of Economics 122(3), 1265-1306.

Werker ED, Ahuja A, and Wendell B., 2006. Male Circumcision and AIDS: The Macroeconomic Impact of a Health Crisis. HBS Working Paper No. 07-025. 
Young, Alwyn, 2005. The Gift of the Dying: The Tragedy of AIDS and the Welfare of Future African Generations. Quarterly Journal of Economics 120(2), 423-466.

Yuksel, Mutlu, 2009. Intergenerational Mobility of Immigrants in Germany: Moving with Natives or Stuck in their Neighborhoods? IZA Discussion Paper 4677.

Zimmerman, David J., 1992. Regression Toward Mediocrity in Economic Stature. American Economic Review 82(3), 409-429. 
Table 1a: Descriptive Statistics for Mothers

\begin{tabular}{lcccc}
\hline \hline & & & & \\
& All & All & HIV-Positive & HIV-Negative \\
& $1990 \mathrm{~s}$ & $2000 \mathrm{~s}$ & $2000 \mathrm{~s}$ & $2000 \mathrm{~s}$ \\
& $(1)$ & $(2)$ & $(3)$ & $(4)$ \\
\hline \multirow{2}{*}{ Years of Schooling } & & & & \\
& 2.436 & 3.574 & 5.687 & 3.345 \\
Poorest & $(3.463)$ & $(3.919)$ & $(3.668)$ & $(3.877)$ \\
& & 0.216 & 0.166 & 0.222 \\
Working Status & & $(0.412)$ & $(0.372)$ & $(0.416)$ \\
& 0.627 & 0.664 & 0.575 & 0.674 \\
Married & $(0.484)$ & $(0.489)$ & $(0.495)$ & $(0.487)$ \\
Number of Children Living & 0.913 & 0.866 & 0.567 & 0.899 \\
& $(0.282)$ & $(0.340)$ & $(0.496)$ & $(0.302)$ \\
Husband's HIV Status & 5.911 & 5.524 & 4.499 & 5.635 \\
& $(2.065)$ & $(1.990)$ & $(1.872)$ & $(1.971)$ \\
Husband's Years of Schooling & & 0.072 & 0.687 & 0.039 \\
Age & 3.633 & $(0.259)$ & $(0.465)$ & $(0.192)$ \\
Rural & $(4.414)$ & 5.039 & 7.768 & 4.885 \\
& 37.964 & $(5.849)$ & $(7.317)$ & $(5.718)$ \\
Group Share & 38.884 & 37.879 & 38.993 \\
N & $(5.501)$ & $(5.455)$ & $(5.154)$ & $(5.475)$ \\
\hline \hline
\end{tabular}

Notes: Summary statistics are for mothers who are 15-49 years old and were born before 1980. Column (1) reports the descriptive statistics from earlier waves of DHS conducted between 1991 and 1996. Columns (2)-(4) present descriptive statistics from recent surveys with HIV-testing data. In columns (2)-(4) only mothers with non-missing HIV status are included. Standard deviations are reported in parentheses. 
Table 1b: Descriptive Statistics for Children

\begin{tabular}{lcccc}
\hline \hline & & & & \\
& All & All & HIV-Positive & HIV-Negative \\
& $1990 \mathrm{~s}$ & $2000 \mathrm{~s}$ & $2000 \mathrm{~s}$ & $2000 \mathrm{~s}$ \\
& $(1)$ & $(2)$ & $(3)$ & $(4)$ \\
\hline \multirow{2}{*}{ Years of Schooling } & 3.439 & 4.444 & 5.927 & 4.283 \\
& $(2.698)$ & $(2.857)$ & $(2.382)$ & $(2.859)$ \\
Progress through School & 0.532 & 0.621 & 0.796 & 0.602 \\
& $(0.417)$ & $(0.384)$ & $(0.301)$ & $(0.388)$ \\
School Attendance & 0.701 & 0.814 & 0.954 & 0.799 \\
Age & $(0.458)$ & $(0.389)$ & $(0.209)$ & $(0.401)$ \\
& 13.465 & 14.076 & 14.482 & 14.032 \\
Female & $(0.499)$ & $(1.210)$ & $(1.362)$ & $(1.185)$ \\
Rural & 0.500 & 0.480 & 0.512 & 0.477 \\
& $(0.500)$ & $(0.500)$ & $(0.500)$ & $(0.499)$ \\
Group Share & 0.666 & 0.701 & 0.628 & 0.709 \\
N & $(0.472)$ & $(0.458)$ & $(0.484)$ & $(0.454)$ \\
\hline \hline
\end{tabular}

Notes: Summary statistics are for children who are 13-17 years old. Column (1) reports the descriptive statistics from earlier waves of DHS conducted between 1991 and 1996. Columns (2)-(4) present descriptive statistics from recent surveys with HIV-testing data. In columns (2)-(4) only children with mothers that have non-missing HIV status are included. Standard deviations are reported in parentheses. 
Table 2: Intergenerational Transmission of Human Capital

\begin{tabular}{|c|c|c|c|}
\hline & $(1)$ & $(2)$ & (3) \\
\hline \multicolumn{4}{|c|}{ Panel A: 2003-2007 } \\
\hline Mother's Year of Schooling & $\begin{array}{l}0.374^{*} \\
(0.006)\end{array}$ & $\begin{array}{l}0.362^{*} \\
(0.006)\end{array}$ & $\begin{array}{l}0.203^{*} \\
(0.007)\end{array}$ \\
\hline$R^{2}$ & 0.403 & 0.410 & 0.509 \\
\hline $\mathrm{N}$ & 8992 & 8984 & 8984 \\
\hline \multicolumn{4}{|c|}{ Panel B: 1991-1996 } \\
\hline Mother's Year of Schooling & $\begin{array}{l}0.422^{*} \\
(0.006)\end{array}$ & $\begin{array}{l}0.420^{*} \\
(0.006)\end{array}$ & $\begin{array}{l}0.230^{*} \\
(0.007)\end{array}$ \\
\hline$R^{2}$ & 0.299 & 0.306 & 0.494 \\
\hline $\mathrm{N}$ & 9562 & 9561 & 9561 \\
\hline Child's Age and Sex & Yes & Yes & Yes \\
\hline Household Characteristics & & Yes & Yes \\
\hline Region Fixed Effects & & & Yes \\
\hline
\end{tabular}

Notes: Mothers with non-missing HIV status and their children are used in the regressions. Household characteristics include mother's age, wealth quintile, marital status, working status and number of children. Column (3) also controls for region dummies and a rural dummy. Each column is from a separate regression with a constant. Robust standard errors are in parentheses. Asterisk denotes significance level $\left({ }^{*}=\mathrm{p}\right.$-value $\left.<.05\right)$. 
Table 3: Effect of Mother's HIV Status on Inheritability of Human Capital

\begin{tabular}{|c|c|c|c|}
\hline & $(1)$ & $(2)$ & (3) \\
\hline \multicolumn{4}{|c|}{ Panel A: Years of Schooling } \\
\hline Mother's Year of Schooling & $\begin{array}{l}0.378^{*} \\
(0.006)\end{array}$ & $\begin{array}{l}0.267^{*} \\
(0.009)\end{array}$ & $\begin{array}{c}0.135^{*} \\
(0.009)\end{array}$ \\
\hline HIV Positive Mother * & $-0.109^{*}$ & $-0.130^{*}$ & $-0.038^{*}$ \\
\hline Mother's Year of Schooling & $(0.020)$ & $(0.019)$ & $(0.018)$ \\
\hline HIV Positive Mother & $\begin{array}{l}1.092^{*} \\
(0.154)\end{array}$ & $\begin{array}{l}1.016^{*} \\
(0.145)\end{array}$ & $\begin{array}{c}0.124 \\
(0.133)\end{array}$ \\
\hline$R^{2}$ & 0.407 & 0.477 & 0.567 \\
\hline $\mathrm{N}$ & 8992 & 8200 & 8200 \\
\hline
\end{tabular}

Panel B: Progress through School

$\begin{array}{lccc}\text { Mother's Year of Schooling } & 0.055^{*} & 0.040^{*} & 0.020^{*} \\ & (0.001) & (0.001) & (0.001) \\ \text { HIV Positive Mother } & -0.018^{*} & -0.021^{*} & -0.006^{*} \\ \text { Mother's Year of Schooling } & (0.003) & (0.003) & (0.003) \\ \text { HIV Positive Mother } & 0.169^{*} & 0.163^{*} & 0.036 \\ & (0.021) & (0.021) & (0.019) \\ R^{2} & 0.314 & 0.367 & 0.478 \\ \mathrm{~N} & 8892 & 8200 & 8200\end{array}$

Panel C: School Attendance

\begin{tabular}{lccc} 
Mother's Year of Schooling & $0.040^{*}$ & $0.029^{*}$ & $0.004^{*}$ \\
& $(0.001)$ & $(0.001)$ & $(0.001)$ \\
HIV Positive Mother & $-0.026^{*}$ & $-0.029^{*}$ & $-0.007^{*}$ \\
Mother's Year of Schooling & $(0.003)$ & $(0.002)$ & $(0.002)$ \\
HIV Positive Mother & $0.202^{*}$ & $0.200^{*}$ & 0.028 \\
& $(0.020)$ & $(0.020)$ & $(0.017)$ \\
$R^{2}$ & 0.174 & 0.194 & 0.380 \\
$\mathrm{~N}$ & 8892 & 8200 & 8200 \\
\hline Child's Age and Sex & Yes & Yes & Yes \\
Household Characteristics & & Yes & Yes \\
Region Fixed Effects & & & Yes \\
\hline \hline
\end{tabular}

Notes: Women with non-missing HIV status and their children are used in the regressions. Household characteristics include household wealth quintile, mother's age, marital and working status and number of children. Column (3) also controls for country and region dummies and a rural dummy. Each column is from a separate regression with a constant. Robust standard errors are reported in parentheses. Asterisk denotes significance level $\left({ }^{*}=p\right.$-value $\left.<.05\right)$. 
Table 4: Determinants of Mother's HIV Status: Probit Regression

Dependent Variable: Mother's HIV Status

\begin{tabular}{lc}
\hline \hline & \\
Age & 0.008 \\
& $(0.007)$ \\
gge $^{2}$ & -0.000 \\
& $(0.000)$ \\
Primary Education & 0.009 \\
& $(0.008)$ \\
Secondary Education & $0.022^{*}$ \\
& $(0.012)$ \\
Tertiary Education & -0.013 \\
& $(0.018)$ \\
Currently Married & $-0.218^{*}$ \\
& $(0.155)$ \\
Formerly Married & -0.004 \\
& $(0.023)$ \\
Rural & -0.014 \\
& $(0.010)$ \\
Poorer & -0.001 \\
& $(0.009)$ \\
Middle & $0.026^{*}$ \\
& $(0.011)$ \\
Richer & $0.038^{*}$ \\
& $(0.013)$ \\
Richest & $0.058^{*}$ \\
& $(0.018)$ \\
$R^{2}$ & 0.208 \\
$\mathrm{~N}$ & 7720 \\
\hline \hline
\end{tabular}

Notes: Country and region dummies are included in the regression. The omitted categories are : "No Education", "Urban", "Never Married", and "Poorest Wealth". Robust standard errors are reported in parentheses. Asterisk denotes significance level $\left({ }^{*}=\mathrm{p}\right.$-value $\left.<.05\right)$. 
Table 5: Effect of Mother's HIV Status on Intergenerational Transmission of Human Capital: Propensity Score Matching

\begin{tabular}{lccc}
\hline \hline & $\begin{array}{c}\text { Years of } \\
\text { Schooling } \\
(1)\end{array}$ & $\begin{array}{c}\text { Progress } \\
\text { through School } \\
(2)\end{array}$ & $\begin{array}{c}\text { School } \\
\text { Attendance } \\
(3)\end{array}$ \\
\hline Mother's Year of Schooling & $\begin{array}{c}0.140^{*} \\
(0.033)\end{array}$ & $\begin{array}{c}0.021^{*} \\
(0.005)\end{array}$ & 0.003 \\
& & & $(0.004)$ \\
HIV Positive Mother* & $-0.062^{*}$ & $-0.011^{*}$ & $-0.010^{*}$ \\
Mother's Year of Schooling & $(0.031)$ & $(0.005)$ & $(0.004)$ \\
& & & \\
HIV Positive Mother & 0.351 & 0.064 & 0.038 \\
& $(0.277)$ & $(0.042)$ & $(0.040)$ \\
$R^{2}$ & & & 0.502 \\
N & 0.597 & 0.523 & 1629 \\
& 1629 & 1629 & \\
\hline Child's Age and Sex & Yes & Yes & Yes \\
Household Characteristics & Yes & Yes & Yes \\
Region Fixed Effects & Yes & Yes & Yes \\
\hline \hline
\end{tabular}

Notes: HIV-positive and HIV-negative women are matched (nearest-neighbor matching without replacement) based on mother's age, marital status, years of schooling and wealth quintile. Only matched sample is used in the regressions. Each column is from a separate regression with a constant. Household characteristics include household wealth quintile, mother's marital and working status and number of children. Each column also controls for country and region dummies and a rural dummy. Robust standard errors are reported in parentheses. Asterisk denotes significance level $\left({ }^{*}=\mathrm{p}\right.$-value $\left.<.05\right)$. 
Table 6: Effect of Mother's HIV Status on Intergenerational Transmission: Channels

\begin{tabular}{lccc}
\hline \hline & $\begin{array}{c}\text { Years of } \\
\text { Schooling } \\
(1)\end{array}$ & $\begin{array}{c}\text { Progress } \\
\text { though School } \\
(2)\end{array}$ & $\begin{array}{c}\text { School } \\
\text { Attendance } \\
(3)\end{array}$ \\
\hline Mother's Year of Schooling & $\begin{array}{c}0.130^{*} \\
(0.013)\end{array}$ & $\begin{array}{c}0.019^{*} \\
(0.002)\end{array}$ & $\begin{array}{c}0.005^{*} \\
(0.002)\end{array}$ \\
HIV Positive Parents* & $-0.079^{*}$ & $-0.011^{*}$ & $-0.017^{*}$ \\
Mother's Year of Schooling & $(0.038)$ & $(0.006)$ & $(0.004)$ \\
HIV Positive Parents & 0.140 & 0.008 & 0.067 \\
& $(0.360)$ & $(0.054)$ & $(0.038)$ \\
Mother Read Newspaper or & $0.180^{*}$ & 0.018 & $-0.020^{*}$ \\
Magazine & $(0.087)$ & $(0.013)$ & $(0.010)$ \\
Listen Radio & & & \\
& $0.195^{*}$ & $0.030^{*}$ & $0.043^{*}$ \\
Watch TV & $(0.077)$ & $(0.012)$ & $(0.014)$ \\
& & & \\
$R^{2}$ & $0.238^{*}$ & $0.034^{*}$ & 0.002 \\
$\mathrm{~N}$ & $(0.092)$ & $(0.014)$ & $(0.016)$ \\
\hline \hline & & & 0.388 \\
& 0.572 & 0.494 & 3773 \\
\hline
\end{tabular}

Notes: Regressions control for father's and mother's characteristics, i.e., age, years of schooling, HIV status, wealth quintile, working status, marital status and number of living children. Other controls are proxies for investment for child's human capital, i.e., mother's propensity to read newspaper or magazines and child's propensity to listen radio and watch TV. Region dummies, rural dummy, child's age and sex are also included in the regressions. Robust standard errors are reported in parentheses. Asterisk denotes significance level $\left({ }^{*}=\mathrm{p}\right.$-value $\left.<.05\right)$. 
Table 7: Descriptive Statistics for Communities

\begin{tabular}{l}
\hline \\
Mean Standard Deviation Min Max
\end{tabular}

Panel A: 2003-2007

$\begin{array}{llllc}\text { Child Years of Schooling } & 4.29 & 1.69 & 1.16 & 7.72 \\ \text { Child School Attendance } & 0.79 & 0.23 & 0.25 & 1.00 \\ \text { Progress through School } & 0.62 & 0.22 & 0.17 & 1.00 \\ \text { Mother Years of Schooling } & 3.53 & 2.58 & 0.27 & 9.24 \\ \text { Father Years of Schooling } & 5.32 & 3.22 & 0.08 & 12.88 \\ \text { HIV Prevalence } & 0.07 & 0.07 & 0.00 & 0.21\end{array}$

Panel B: 1991-1996

\begin{tabular}{llllc} 
Child Years of Schooling & 3.65 & 1.69 & 0.86 & 6.95 \\
Child School Attendance & 0.72 & 0.28 & 0.20 & 1.00 \\
Progress through School & 0.57 & 0.26 & 0.14 & 1.08 \\
Mother Years of Schooling & 2.63 & 1.98 & 0.00 & 7.55 \\
Father Years of Schooling & 3.88 & 2.88 & 0.00 & 12.29 \\
\hline \hline
\end{tabular}

Notes: "Community" refers to country by region cell. HIV prevalence is based on both men and women while mother's and child's education variables refer to women with non-missing HIV status and their children only. 
Table 8: Effect of Community HIV Prevalence on Intergenerational Transmission: OLS

\begin{tabular}{lccc}
\hline \hline & $\begin{array}{c}\text { Years of } \\
\text { Schooling } \\
(1)\end{array}$ & $\begin{array}{c}\text { Progress } \\
\text { through School } \\
(2)\end{array}$ & $\begin{array}{c}\text { School } \\
\text { Attendance } \\
(3)\end{array}$ \\
\hline Mother's Year of Schooling & $\begin{array}{c}0.217^{*} \\
(0.024)\end{array}$ & $\begin{array}{c}0.035^{*} \\
(0.004)\end{array}$ & $\begin{array}{c}0.026^{*} \\
(0.005)\end{array}$ \\
& & & \\
Community HIV * & $-0.007^{*}$ & $-0.001^{*}$ & $-0.002^{*}$ \\
Mother's Year of Schooling & $(0.002)$ & $(0.000)$ & $(0.000)$ \\
& & & \\
Community HIV Prevalence & $0.059^{*}$ & $0.010^{*}$ & $0.014^{*}$ \\
& $(0.018)$ & $(0.003)$ & $(0.003)$ \\
$R^{2}$ & & & \\
N & 0.540 & 0.451 & 0.342 \\
\hline Child's Age and Sex & 7376 & 7376 & 7376 \\
Household Characteristics & Yes & Yes & Yes \\
Country Fixed Effects & Yes & Yes & Yes \\
\hline \hline
\end{tabular}

Notes: HIV negative mothers and their children are included in the regressions. "Community HIV Prevalence" refers to the fraction of men and women with positive HIV status in each region. Regressions control for child's and mother's age, child's sex, household wealth quntile, mother's marital and working status, number of living children and country dummies. Each column is from a separate regression with a constant. Robust standard errors clustered at the community level are reported in parentheses. Asterisk denotes significance level $\left({ }^{*}=\mathrm{p}\right.$-value $\left.<.05\right)$. 
Table 9: Effect of Community HIV Prevalence on Intergenerational Transmission: Fixed Effect

\begin{tabular}{lccc}
\hline \hline & $\begin{array}{c}\text { Years of } \\
\text { Schooling } \\
(1)\end{array}$ & $\begin{array}{c}\text { Progress } \\
\text { through School } \\
(2)\end{array}$ & $\begin{array}{c}\text { School } \\
\text { Attendance } \\
(3)\end{array}$ \\
\hline Mother's Year of Schooling & $\begin{array}{c}0.250^{*} \\
(0.014)\end{array}$ & $\begin{array}{c}0.039^{*} \\
(0.002)\end{array}$ & $\begin{array}{c}0.027^{*} \\
(0.003)\end{array}$ \\
& & & \\
Community HIV * & $-0.004^{*}$ & $-0.001^{*}$ & $-0.002^{*}$ \\
Mother's Year of Schooling & $(0.001)$ & $(0.000)$ & $(0.000)$ \\
& & & \\
2003-2007 & $0.285^{*}$ & $0.043^{*}$ & $0.085^{*}$ \\
& $(0.064)$ & $(0.010)$ & $(0.012)$ \\
$R^{2}$ & & & \\
N & 0.495 & 0.454 & 0.402 \\
\hline Child's Age and Sex & 17311 & 17311 & 17311 \\
Household Characteristics & Yes & Yes & Yes \\
Region Fixed Effects & Yes & Yes & Yes \\
Time Fixed Effects & Yes & Yes & Yes \\
\hline \hline
\end{tabular}

Notes: Surveys used in the regressions are Burkina Faso (2003, 1992), Cameron (2004, 1991), Cote d'Ivorie (2005, 1994), Ghana (2003, 1993/1994), Kenya (2003, 1993), Mali (2006, 1995/1996), Malawi (2004, 1992), Niger (2006, 1992), Senegal (2005, 1992), Zambia (2007, 1992) and Zimbabwe (2005/2006, 1994). HIV negative mothers and their children are included in the regressions. All regressions include community and time period fixed effects. Other controls are child's and mother's age, child's sex, household wealth quintile, mother's marital and working status and number of living children. Each column is from a separate regression with a constant. Robust standard errors clustered by the community and time period are reported in parentheses. Asterisk denotes significance level $\left({ }^{*}=\mathrm{p}\right.$-value $\left.<.05\right)$. 
Table A-1: DHS Data

\begin{tabular}{lcccc}
\hline \hline & Survey Year & $\begin{array}{c}\text { Main Survey } \\
\text { Response Rate } \\
(2)\end{array}$ & $\begin{array}{c}\text { HIV Testing } \\
\text { Response Rate } \\
(3)\end{array}$ & $\begin{array}{c}\text { HIV Prevalence } \\
(\%) \\
(4)\end{array}$ \\
\hline Burkina Faso & 2003 & 96.3 & 92.3 & 1.82 \\
Cameroon & 2004 & 94.3 & 92.1 & 6.63 \\
Cote d'Ivorie & 2005 & 89.8 & 79.1 & 4.72 \\
Ghana & 2003 & 95.7 & 89.3 & 2.71 \\
Kenya & 2003 & 94.0 & 76.3 & 8.69 \\
Malawi & 2004 & 95.7 & 70.4 & 13.32 \\
Mali & 2006 & 95.7 & 92.0 & 1.39 \\
Niger & 2005 & 95.6 & 90.7 & 0.71 \\
Senegal & 2005 & 93.7 & 84.5 & 0.88 \\
Zambia & 2007 & 96.5 & 74.7 & 14.2 \\
Zimbabwe & $2005 / 2006$ & 90.2 & 75.9 & 21.12 \\
\hline \hline
\end{tabular}

Notes: Column (1) is the survey year. Column (2) gives the response rate of women to the main survey. Column (3) reports the fraction of sample who were sampled to be HIV-tested and give their consent for testing. Based on the reason for non-response, individuals who were not tested are divided into four categories: those who refused testing, those who were interviewed in the survey but who were absent when the health worker arrived for testing, those who were never interviewed, and those who had missing test results due to technical problems. Column (4) reports the national HIV prevalence. 
Table A-2: Importance of Paternal Education

\begin{tabular}{lccc}
\hline \hline & $(1)$ & $(2)$ & $(3)$ \\
\hline \multirow{4}{*}{ Panel A: 2003-2007 } & & \\
Father's Year of Schooling & & & \\
& $0.178^{*}$ & $0.165^{*}$ & $0.079^{*}$ \\
& $(0.026)$ & $(0.025)$ & $(0.017)$ \\
$R^{2}$ & & & \\
$\mathrm{~N}$ & 0.263 & 0.282 & 0.426 \\
& 4623 & 4619 & 4619 \\
& & & \\
Father's Year of Schooling & $0.366^{*}$ & $0.372^{*}$ & $0.219^{*}$ \\
& $(0.012)$ & $(0.014)$ & $(0.016)$ \\
$R^{2}$ & & & \\
$\mathrm{~N}$ & 0.361 & 0.371 & 0.539 \\
\hline Child's Age and Sex & 1711 & 1393 & 1393 \\
\hline Household Characteristics & Yes & Yes & Yes \\
Country Fixed Effects & & Yes & Yes \\
\hline \hline
\end{tabular}

Notes: Fathers with non-missing HIV status and their children are used in the regressions. Household characteristics include household wealth quintile, father's marital and working status and number of children. Column (3) also controls for region dummies and rural dummy. Each column is from a separate regression with a constant. Robust standard errors are reported in parentheses. Asterisk denotes significance levels $\left({ }^{*}=\right.$ p-value $\left.<.05\right)$. 